\title{
Coumarin's Anti-Quorum Sensing Activity Can Be Enhanced When Combined with Other Plant-Derived Small Molecules
}

\author{
Dmitry Deryabin, Kseniya Inchagova, Elena Rusakova * and Galimzhan Duskaev
}

check for updates

Citation: Deryabin, D.; Inchagova, K.; Rusakova, E.; Duskaev, G.

Coumarin's Anti-Quorum Sensing Activity Can Be Enhanced When

Combined with Other Plant-Derived Small Molecules. Molecules 2021, 26, 208. https://doi.org/10.3390/ molecules 26010208

Academic Editor: Maria João Matos Received: 30 November 2020 Accepted: 18 December 2020 Published: 3 January 2021

Publisher's Note: MDPI stays neutral with regard to jurisdictional clai$\mathrm{ms}$ in published maps and institutional affiliations.

Copyright: () 2021 by the authors. Licensee MDPI, Basel, Switzerland. This article is an open access article distributed under the terms and conditions of the Creative Commons Attribution (CC BY) license (https:// creativecommons.org/licenses/by/ $4.0 /)$.
Federal Research Centre of Biological Systems and Agro-technologies of the Russian Academy of Sciences, Orenburg 460000, Russia; dgderyabin@yandex.ru (D.D.); ksenia.inchagova@mail.ru (K.I.); gduskaev@mail.ru (G.D.)

* Correspondence: elenka_rs@mail.ru; Tel.: +7-919-860-24-78

\begin{abstract}
Coumarins are class of natural aromatic compounds based on benzopyrones $(2 \mathrm{H}-1$ benzopyran-2-ones). They are identified as secondary metabolites in about 150 different plant species. The ability of coumarins to inhibit cell-to-cell communication in bacterial communities (quorum sensing; QS) has been previously described. Coumarin and its derivatives in plant extracts are often found together with other small molecules that show anti-QS properties too. The aim of this study was to find the most effective combinations of coumarins and small plant-derived molecules identified in various plants extracts that inhibit QS in Chromobacterium violaceum ATCC 31532 violacein production bioassay. The coumarin and its derivatives: 7-hydroxycoumarin, 7.8-dihydroxy-4-methylcoumarin, were included in the study. Combinations of coumarins with gamma-octalactone, 4-hexyl-1.3-benzenediol, 3.4.5-trimethoxyphenol and vanillin, previously identified in oak bark (Quercus cortex), and eucalyptus leaves (Eucalyptus viminalis) extracts, were analyzed in a bioassay. When testing two-component compositions, it was shown that 7.8dihydroxy-4-methylcoumarin, 4-hexyl-1.3-benzendiol, and gamma-octalactone showed a supra-additive anti-QS effect. Combinations of all three molecules resulted in a three- to five-fold reduction in the concentration of each compound needed to achieve $\mathrm{EC}_{50}$ (half maximal effective concentration) against QS in C. violaceum ATCC 31532.
\end{abstract}

Keywords: coumarins; quorum sensing; QS inhibitors; plant-derived molecules; Chromobacterium violaceum

\section{Introduction}

Coumarins are a class of natural compounds based on benzopyrones (2H-1-benzopyran2-ones) [1]. These compounds can be classified depending on the core's structure and the presence of substituents. There are the "simplest" coumarins (e.g., coumarin and dihydrocoumarin), followed by oxy-, meth-oxy-, and methylenedioxycoumarins with various substitutions in benzene/pyron rings (e.g., umbelliferon, 3-hydroxycoumarin, and scopoletin). The furancoumarins (e.g., bergamotin) contain an additional condensed furan core. Other, more structurally complex compounds are the result of coumarin condensation with pyran, benzene, and benzofuran rings. Most of the compounds of this class in plants are found in the free state, and only a small number are found in glycosides with D-glucose attached to the $\mathrm{C} 6, \mathrm{C} 7$, or $\mathrm{C} 8$ atoms of the coumarin nucleus [2].

Currently, coumarins are identified as secondary metabolites in about 150 different plant species distributed in almost 30 families, of which the most important are Rutaceae, Umbelliferae, Clusiaceae, Guttiferae, Caprifoliaceae, Oleaceae, Nyctaginaceae, and Apiaceae [3]. These substances are synthesized from phenylalanine via the shikimic acid formation pathway (hydroxylation, glycolysis, and cyclization of cinnamic acid) [4], and often, several different coumarins are found in the same plant.

Coumarins proposed for medical use due to their proven biological activity. They are showed anti-ulcerogenic [5], antiparasitic [6], anti-inflammatory [7-11], and other properties [12-14]. They are also antioxidant [15], and anticoagulant compounds [16-19]. As such, they can be defined as new pharmaceutical candidates [20]. 
The ability of coumarins to inhibit cell-to-cell communication in bacterial communitiesbetter known as "quorum sensing" (QS) — has been discovered relatively recently. Briefly: QS is a special type of regulator of bacterial gene expression that functions at a high microbial population density. Depending on the chemical nature of the autoinducer, QS can be divided into several types: 1) LuxI/LuxR type (autoinducers-acylated homoserin lactones); 2) type II QS systems (autoinducers-furanone derivatives); 3) QS systems with Gram-positive bacteria (autoinducers-short oligopeptides); 4) QS systems with autoinducers of various natures (e.g., epinephrine, norepinephrine). The first of the described and most common QS systems is a two-component system of the LuxI/LuxR type inherent in many bacterial pathogens [21] where it activates the synthesis of virulence factors and the biofilms formation.

Because the search for plant-derived molecules with anti-QS activity is very actual, the coumarins are interesting object for this screening. Experimental observations of the anti-QS activity of coumarin are mainly related to Gram-negative bacteria that use a LuxI/LuxR type communication system, e.g., Pseudomonas. aeruginosa (in which coumarin suppress of phenazine biosynthesis, and motility) and Aliivibrio fischeri (coumarin inhibits the bioluminescence) [22]. Another simple coumarin, i.e., dihydrocoumarin, effectively inhibited QS-dependent biosynthesis of violacein in Chromobacterium violaceum [23]. The subsequent comparative analysis of seven hydroxycoumarin derivatives in relation to the violacein biosynthesis in C. violaceum showed that the promising anti-QS effect is characteristic of 3-hydroxycoumarin [24]. The identification of other functional substitutions of coumarin core, which led to disruption of the bacterial biofilm formation and, at the same time, inhibits QS development, was done by Reen [4]. This variant of bioactivity was also characteristic of a larger group of compounds, including furanocumarins: bergamottin and 6.7-dihydroxybergamottin. Interestingly, the last two compounds found in citrus fruits (Citrus bergamia, Citrus maxima, and Citrus $\times$ paradisi) showed their activity against bacteria that use both LuxI/LuxR-type and type II QS system [25].

Significantly, coumarin and its derivatives are often found together with other plantderived small molecules that also have anti-QS properties. At the same time, our previous studies have shown that such molecules can act synergistically in a single plant [26,27]; however, until now, the possible combination of coumarins and small plant-derived molecules that are part of various plant extracts remains open.

The aim of this study was to find the most effective combinations of coumarins with small plant-derived molecules previously identified in extracts of oak bark (Quercus cortex), and eucalyptus leaves (Eucalyptus viminalis) to inhibit LuxI/LuxR-type quorum sensing in C. violaceum ATCC (American Type Culture Collection) 31532.

\section{Results}

2.1. Effect of Coumarin and Its Derivatives in Chromobacterium violaceum ATCC 31532 Violacein Production Bioassay

Cultivation of C. violaceum ATCC 31532 with coumarin, 7-hydroxycoumarin, and 7.8dihydroxy-4-methylcoumarin followed registration of the optical density values $\left(\mathrm{OP}_{450}\right)$ of bacterial biomass and violacein production $\left(\mathrm{OP}_{600}\right)$, allowed us to evaluate their effect on the growth and QS-dependent biosynthesis in the bioassay. All tested components showed antibacterial activity as follows: minimum inhibitory concentration $\left(\mathrm{MIC}_{50}\right)=2.689 \mathrm{mg} / \mathrm{mL}$ and $\mathrm{MIC}_{100}=3.650 \mathrm{mg} / \mathrm{mL}$ for coumarin; $\mathrm{MIC}_{50}=0.497 \mathrm{mg} / \mathrm{mL}$ and $\mathrm{MIC}_{100}=1.267 \mathrm{mg} / \mathrm{mL}$ for 7-hydroxycoumarin and $\mathrm{MIC}_{50}=0.325 \mathrm{mg} / \mathrm{mL}$ and $\mathrm{MIC}_{100}=2.400 \mathrm{mg} / \mathrm{mL}$ for 7.8-dihydroxy4-methylcoumarin. Simultaneously, sub-inhibitory concentrations of these compounds provided an anti-QS effect evaluated by inhibition on pigment violacein production, which was expressed as follows: effective concentration $\left(\mathrm{EC}_{50}\right)=1.105 \mathrm{mg} / \mathrm{mL}$ and $\mathrm{EC}_{100}=3.650 \mathrm{mg} / \mathrm{mL}$ for coumarin; $\mathrm{EC}_{50}=0.199 \mathrm{mg} / \mathrm{mL}$ and $\mathrm{EC}_{100}=0.633 \mathrm{mg} / \mathrm{mL}$ for 7-hydroxycoumarin and $\mathrm{EC}_{50}=0.150 \mathrm{mg} / \mathrm{mL}$ and $\mathrm{EC}_{100}=1.200 \mathrm{mg} / \mathrm{mL}$ for 7.8-dihydroxy-4-methylcoumarin (Table 1). Thus, the highest anti-QS activity was demonstrated by 7.8-dihydroxy-4methylcoumarin, and this coumarin derivative was taken for further studies on the combination of small plant-derived molecules. 
Table 1. Effects of coumarin, 7-hydroxycoumarin and 7.8-dihydroxy-4-methylcoumarin $(\mathrm{mg} / \mathrm{mL})$ on growth and QS-controlled violacein pigment biosynthesis in C. violaceum ATCC 31532.

\begin{tabular}{ccccc}
\hline \multirow{2}{*}{ Tested Compound } & \multicolumn{2}{c}{ Characteristics of } & \multicolumn{2}{c}{ Characteristics of Anti-QS } \\
& Antibacterial Activity, $\mathbf{~ m g / m L}$ & \multicolumn{2}{c}{ Activity, mg/mL } \\
MIC $_{\mathbf{1 0 0}}$ & $\mathbf{M I C}_{\mathbf{5 0}}$ & EC $_{\mathbf{1 0 0}}$ & EC $_{\mathbf{5 0}}$ \\
\hline Coumarin & 3.650 & 2.689 & 3.650 & 1.105 \\
7-hydroxycoumarin & 1.267 & 0.497 & 0.633 & 0.199 \\
7.8-dihydroxy-4- & 2.400 & 0.325 & 1.200 & 0.150 \\
methylcoumarin & & & & \\
\hline
\end{tabular}

2.2. Analysis of the Combined Use of Coumarin Derivatives (7.8-Dihydroxy-4-methylcumarin) with Other Small Plant-Derived Molecules in C. violaceum ATCC 31532

Results were obtained for combinations of 7.8-dihydroxy-4-methylcumarin (identified in Baikal skullcap extract) with small plant-derived molecules from oak bark (4-hexyl-1.3benzenediol, 3.4.5-trimethoxyphenol, vanillin) or in eucalyptus leaves (gamma-octalactone), which have own anti-QS activity preliminary in C. violaceum ATCC 3153 bioassay. While most coumarins combinations showed simple additivity, some two-component mixtures led to pronounced mutual strengthening of anti-QS activity, which was evaluated as a synergetic (supra-additive) effect in 2D isobolographic analysis. The supra-additivity was revealed in combination of 7.8-dihydroxy-4-methylcoumarin with 4-hexyl-1.3-benzenediol (Figure 1a) as well as in 7.8-dihydroxy-4-methylcoumarin and gamma-octalactone mixtures (Figure 1b), where cultivation of C. violaceum ATCC 31532 in media enriched these paired molecular compositions showed a two-to four-fold decrease in the concentrations of each compound to achieve 50\% inhibition of QS-controlled violacein biosynthesis. In turn, some combination of small molecules from oak bark and eucalyptus leaves showed the antagonistic (infra-additive) effect achieved in the compositions gamma-octalactone and vanillin, gamma-octalactone and 3.4.5-trimethoxyphenol, while the combinations gammaoctalactone and 4-hexyl-1.3-benzenediol have a supra-additive effect.

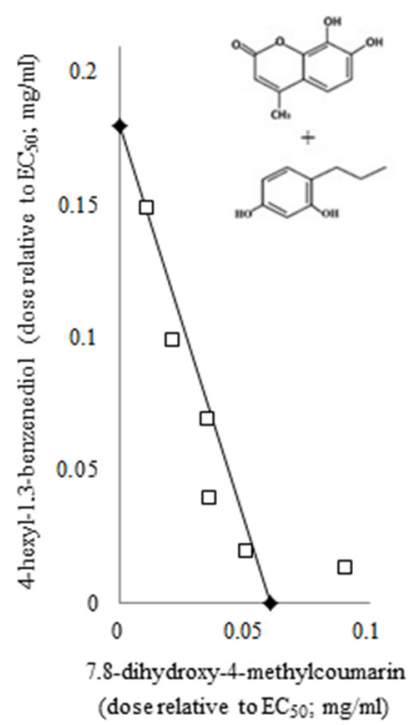

(a)

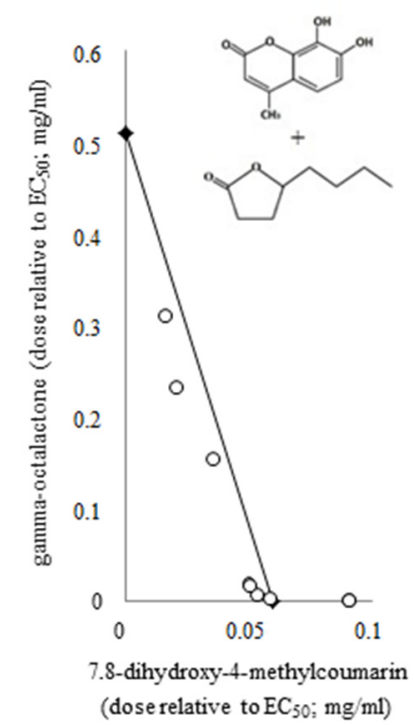

(b)

Figure 1. 2D isobolographic analysis of the combined use of 7.8-dihydroxy-4-methylcoumarin and 4-hexyl-1.3-benzenediol (a), 7.8-dihydroxy-4-methylcoumarin and gamma-octalactone (b) on the QS-controlled violacein biosynthesis in C. violaceum ATCC 31532. Isoboles are represented as straight lines connecting the $\mathrm{EC}_{50}$ concentrations of each compounds. The points under the isoboles correspond to the supra-additive effect. 
On this basis the further research on the combined use of the small molecules from Baikal skullcap, oak bark, and eucalyptus leaves included 7.8-dihydroxy-4-methylcoumarin, 4-hexyl-1.3-benzenediol, and gamma-octalactone, because all pairwise combination of these compounds showed supra-additive anti-QS effect in C. violaceum ATCC 31532 bioassay.

2.3. Evaluation of the Effect of a Three-Component Composition of Small Plant-Derived Molecules on the Quorum Sensing in C. violaceum ATCC 31532

The bioassay of small plant-derived molecules composition, which included various ratios of 7.8-dihydroxy-4-methylcoumarin, 4-hexyl-1.3-benzenediol and gamma-octalactone, confirmed supra-additive effect of two-component composition, and first showed synergy of three-component composition which manifested in the location of majority of the experimental points below the 3D isobole plane (Figure 2).

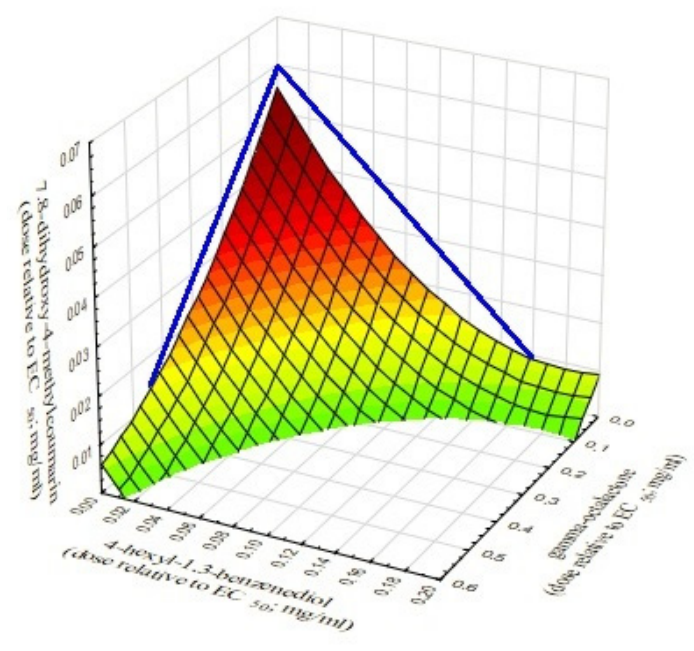

(a)

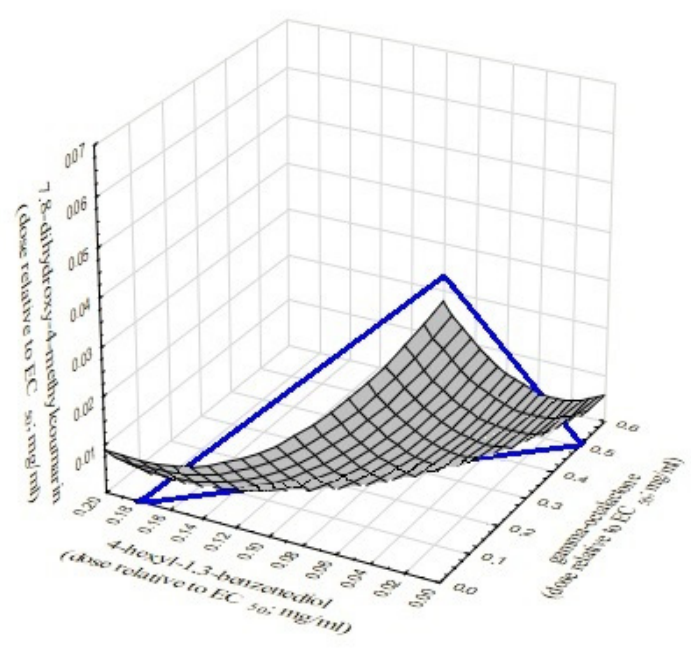

(b)

Figure 2. 3D isobolographic analysis of the combined use of 7.8-dihydroxy-4-methylcoumarin, 4-hexyl-1.3-benzenediol, and gamma-octalactone against the QS-controlled violacein biosynthesis in C. violaceum ATCC 31532: (a) front view; (b) back view. The $3 \mathrm{D}$ isobole is represented as a blue triangle, the vertices of which correspond to $50 \%$ violacein biosynthesis inhibition $\left(\mathrm{EC}_{50}\right)$ for each compound; the "sail" plane show the supra-additive effect of the experimental samples under the $3 \mathrm{D}$ isobole plane.

Figure 2 shows a 3D isobole in the form of a triangle, the vertices of which connect the concentrations of each compounds that cause the same biological effect $\mathrm{EC}_{50}(50 \%$ inhibition of violacein biosynthesis in C. violaceum ATCC 31532 bioassay). At the point of maximum supra-additive effect, with the ratio of tested compounds set to 0.6:1:0.8, the concentrations of each compound were three- to five- lower than the concentrations of individual compounds required to achieve $\mathrm{EC}_{50}$. Importantly, the supra-additive effect was detected in at least $85 \%$ of samples with various rations of 7.8-dihydroxy-4-methylcoumarin, 4-hexyl-1.3-benzenediol and gamma-octalactone.

Thus, the results of our study described original compositions of various in structure small plant-derived molecules of different origins: 7.8-dihydroxy-4-methylcoumarin from Baikal skullcap, 4-hexyl-1.3-benzenediol from oak bark, and gamma-octalactone from eucalyptus leaves, which enhance each other's anti-quorum activity. In such composition, the content of coumarin's derivative can be significantly decreased while maintaining the anti-QS effect, which makes it possible to avoid unfavorable manifestations of the bioactivity of this group of compounds. 


\section{Discussion}

Coumarins have a wide range of biological properties including antiviral, antimicrobial, anti-inflammatory, and other bioactivities. Some coumarins are approved for use in the treatment of various diseases [28-31]. The most important are vitamin $\mathrm{K}$ antagonists, such as warfarin, phenprocumone, or acenocumarol, which are used as anticoagulants [32,33]. Numerous studies have also shown that these compounds do not exhibit significant toxicity to humans and animals $\left(\mathrm{LD}_{50}=275 \mathrm{mg} / \mathrm{kg}\right)$, and are only moderately toxic to the liver and kidneys [34]. In this study we used coumarin and its derivatives at concentrations significantly lower than their $\mathrm{LD}_{50}$ for mammals [35-37].

The novel variant of coumarins bioactivity is anti-QS effect that disrupt cell-to-cell chemical communication in bacteria. In this study we continued this direction and followed the path of analyzing the coumarins compositions with other plant-derived molecules in order to enhance the anti-QS effect.

Using C. violaceum ATCC 31532 bioassay we found anti-QS effect at sub-inhibitory concentrations of coumarin, 7-hydroxycoumarin, and 7.8-dihydroxy-4-methylcoumarin, that is in good agreement with the same activity of other coumarin derivatives: esculetin (6.7-dihydroxycoumarin) [38,39], scopoletin (7-hydroxy-5-methoxycoumarin) [40], furanocoumarin [25], nodakenetin, fraxin [41], and fizetin [42]. This allows us to state the universality of this bioactivity variant for compounds in this group.

Important, that 7.8-dihydroxy-4-methylcoumarin was characterized as the most effective anti-QS compound in this study. This data has not been previously reported anywhere, whereas the described 7.8-dihydroxy-4-methylcoumarin bioactivity comprised its antioxidant properties only $[43,44]$. At the same time, its structural features, particularly the hydroxy groups positions, well-corresponded to all known anti-QS active coumarins [23-25]. Our results were consistent with those of Yang et al. which noted a significant increase in the antibacterial effect upon the hydroxylation of coumarins at positions 6, 7, or 8 [45]. Our data also partially agreed with the studies of Lee et al., who showed that hydroxylation at position 7 increased anti-QS activity, while dihydroxylation of coumarin at positions 6 and 7 decreased this activity in comparison to conventional coumarin [46].

The next step was to combine 7.8-dihydroxy-4-methylcoumarin with other small plant-derived molecules in order to get mutual potentiation of the final anti-QS effect. The originality of the proposed approach was that we combined molecules from different plant sources. When testing two-component compositions, it was shown for the first time that 7.8-dihydroxy-4-methylcoumarin, 4-hexyl-1.3-benzendiol, and gamma-octalactone demonstrated a synergetic (supra-additive) anti-Qs effect, and combining all three molecules together decreased the concentration of each compound required to achieve $\mathrm{EC}_{50}$ in the composition by three-to-five-fold.

Discussing the mechanism of revealed super-additive effect we assumed that it based on the complementary bioactivity mechanisms for each compound (Figure 3). In this concept, gamma-octolactone is structurally close to LuxI/LuxR quorum sensing autoinducers (acylated homoserine lactones) and probably interferes with him for receptor binding. The 4-hexyl-1.3-benzenediol have a not fully identified mechanism, shown in one of our previous study $[47,48]$, which repress the sensitivity of bacterial cells to autoinducers. Coumarins are characterized by a special mechanism through inhibition of the metabolism of cyclic 3',5'-diguanilate (c-di-GMP), an intracellular intermediate that is involved in the regulation of bacterial exopolysaccharide synthesis, biofilm formation, adhesion, and virulence [24]. Doing together, these three compounds block the quorum sensing development at different stages, which is manifested in their super-additive anti-QS effect (Figure 3). 


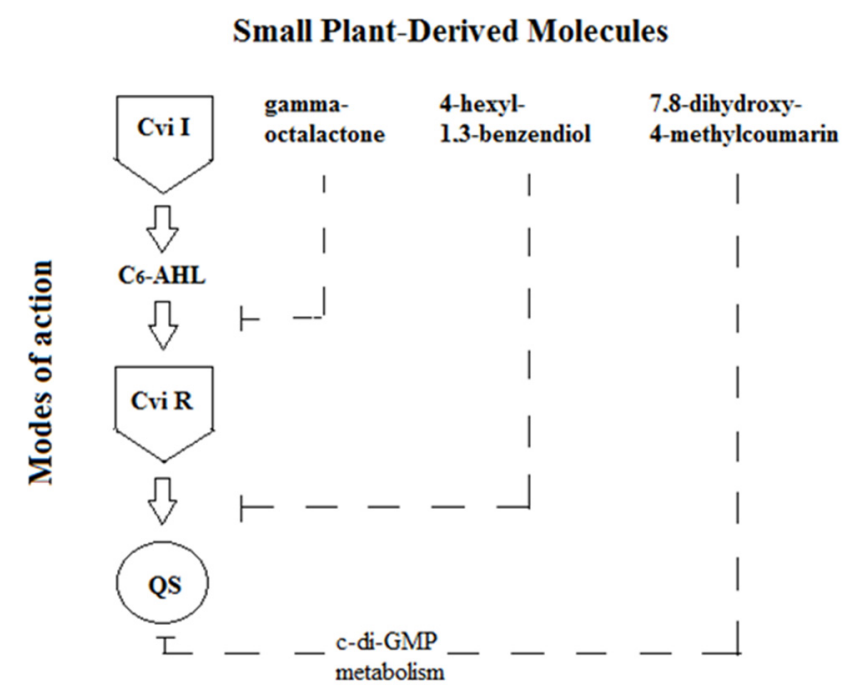

Figure 3. Proposed mechanism of supra-additive anti-QS effect of molecular composition consists of 7.8-dihydroxy-4-methylcoumarin, 4-hexyl-1.3-benzendiol, and gamma-octalactone.

The practical aspect of these results assumes the combined use of coumarin derivatives and other small plant-derived molecules to combat bacterial pathogens of plants, animals, and humans that use quorum sensing systems for the induction of virulence factors and biofilm formation. The implementation of this approach is to use an artificial molecular composition consists of 7.8-dihydroxy-4-methylcoumarin, 4-hexyl-1.3-benzendiol, and gamma-octalactone or the plant materials mixtures with high content of these compounds: Baikal skullcap (Scutellaria baicalensis), oak bark (Quercus cortex), and eucalyptus leaves (Eucalyptus viminalis). Due to the high biological activity of these compositions, they can become a substitute for antibiotics in feeding of farm animals, and should also be considered as candidate pharmaceuticals for further preclinical and clinical studies.

\section{Materials and Methods}

\subsection{Chemical Compounds}

Coumarin and its derivatives were used to inhibit QS in Chromobacterium violaceum ATCC 31532: coumarin (2H-chromene-2OH; CAS 91-64-5) (Figure 4A), 7-hydroxycoumarin (7-hydroxy-2H-1-benzopyran-2-one; CAS 93-35-6) (Figure 4B), and 7.8-dihydroxy-4methylcoumarin (4-methyldafnetin; CAS 2107-77-9) (Figure 4C).

A<smiles>O=c1ccc2ccccc2o1</smiles>

B<smiles>O=c1ccc2cccc(O)c2o1</smiles>

C<smiles>Cc1cc(=O)oc2c(O)c(O)ccc12</smiles>

Figure 4. Structural formula of coumarin (A), 7-hydroxycoumarin (B), and 7.8-dihydroxy-4-methylcoumarin (C).

Small plant-derived molecules with previously reported anti-QS activity that were identified in extracts of oak bark (Quercus cortex), and eucalyptus leaves (Eucalyptus viminalis), were tested in combinations with coumarin derivatives. The analysis included gammaoctalactone (2(3H)-furanone; CAS 147852-83-3), 4-hexyl-1.3-benzenediol (4-n-propylresorcinol; CAS 13331-19-6), 3.4.5-trimethoxyphenol (antiarol; CAS 642-71-7), vanillin (4-hydroxy-3methoxy benzaldehyde; CAS 121-33-5). 
Each of these compounds had a purity at least $99 \%$ and was purchased from SigmaAldrich (St. Louis, MO, USA).

\subsection{Bacterial Strain}

The wild strain of C. violaceum ATCC 31532 that possessed a two-component LuxI/LuxRtype QS system, was used in bioassay. In this strain CviI synthase (LuxI analog) produce autoinducer N-hexanoyl-L-homoserin lactone (C6-AHL) which bond CviR receptor protein (LuxR analog) and activate QS-controlled transcription of several target genes including vioABEDC operon [49]. The encoded VioA, VioB, VioE, VioD, and VioC proteins form a biosynthetic pathway for blue-violet pigment violacein with a maximum absorption at $585 \mathrm{~nm}$. The amount of pigment in the bacterial culture allowed us to directly assess the QS activity.

4.3. Methods for Investigating Anti-QS Activity of Coumarin Derivatives in C. violaceum ATCC 31532 Bioassay

To determine the anti-QS activity of each compound in Luria-Bertani (LB) broth, double dilutions $(n \times 2)$ were prepared. The similar samples of LB-broth that did not contain tested compounds were used as positive (growth of the test strain) and negative (sterile) controls. Glass vessels containing $2 \mathrm{~mL}$ of experimental dilutions or control samples were inoculated $20 \mu \mathrm{l}$ of a one-day C. violaceum ATCC 31532 culture and cultivated in a static mode at $27^{\circ} \mathrm{C}$. The results were evaluated using a multifunctional microplate reader Infinite 200 PRO (Tecan, Männedorf, Switzerland). The optical density at $450 \pm 5 \mathrm{~nm}$ $\left(\mathrm{OP}_{450}\right)$ measured the bacterial biomass and evaluated the effect of the studied compounds on bacterial growth, while the violacein pigment after its ethanol extraction was determined at $600 \pm 5 \mathrm{~nm}\left(\mathrm{OP}_{600}\right)$, which was an indicator of the effect on the QS system. The absorption values of the negative control were subtracted. The antibacterial effect of the studied compounds was presented by the $\mathrm{MIC}_{100}$ and $\mathrm{MIC}_{50}$ values, which were minimal inhibitory concentrations that caused $100 \%$ and $50 \%$ growth suppression for the test strain relative to the positive control. The inhibition of quorum sensing was expressed as $\mathrm{EC}_{100}$ and $\mathrm{EC}_{50}$ values, which were equal to $100 \%$ and $50 \%$ inhibition of violacein pigment biosynthesis in grown culture, respectively.

\subsection{Evaluation of the Combined Use of Coumarins and Small Plant-Derived Molecules against in} C. violaceum ATCC 31532

To examine the combined effect, double dilutions of test compounds were introduced into plastic 96-well plates in perpendicular directions (connection X: connection Y), so that each well contained their individual ratio. Comparison samples were a series of dilutions containing only one of the tested compounds, as well as positive and negative controls. Further inoculation of $C$. violaceum ATCC 31532, cultivation, and recording of the study results were performed as described above. The effect of the paired compositions was evaluated using isobolographic analysis [49], which is based on the construction of 2D isoboles (i.e., lines connecting the $\mathrm{EC}_{50}$ values for the studied compounds $\mathrm{X}$ and $\mathrm{Y}$, on the abscissa and ordinate axes) followed by drawing points on this graph which corresponding to the combined effect of compounds $\mathrm{X}$ and $\mathrm{Y}$ at different concentration ratios. The location of such points on the isobole line corresponded to an additivity (summation effect), their placement above the isobole line described an infra-additive effect (antagonism), and below the isobole showed a supra-additive (synergetic) effect.

Studies of a three-component composition were beginning from the formation of a series of 96-well plates containing the double dilutions of compounds $X$ and $Y$, as described above. On the next step the wells in each plate were filled with a certain concentration of compound $\mathrm{Z}$ (i.e., the total number of used 96-well plates was equal to the number of tested concentrations of compound $Z$ ). The control samples were a dilution series containing only compound $\mathrm{X}$, only compound $\mathrm{Y}$, or only compound $\mathrm{Z}$, as well as positive and negative controls. Wells were inoculated with C. violaceum ATCC 31532, cultivated and analyzed 
as described above. The effect of the three-component compositions was evaluated using three-dimensional (3D) isoboles plotted based on the $\mathrm{EC}_{50}$ values for each compound.

\subsection{Statistical Analysis}

All values presented a mean of the 5 experiments. The obtained results were processed using methods of statistical variance in Excel for Windows 10.

\section{Conclusions}

In this study, coumarin and its derivatives were tested against quorum sensing in Chromobacterium violaceum ATCC 31532, and promising activity was shown in 7.8-dihydroxy-4methylcoumarin. This compound previously detected in Baikal skullcap (Scutellaria baicalensis) was combined with other small plant-derived molecules identified in extracts of oak bark (Quericus cortex), and eucalyptus leaves (Eucalyptus viminalis). It has been shown that 7.8dihydroxy-4-methylcoumarin, 4-hexyl-1.3-benzenediol and gamma-octalactone exhibit a supra-additive anti-QS effect in two-component combinations, and the combination of all three molecules reduces the concentration of each of them required for reaching $\mathrm{EC}_{50}$ against QS, by three- to five- times. It was proposed that the super-additive effect is based on various bioactivity mechanisms of tested molecules, which disrupt the QS development at different stages. The results provide a use for small plant-derived molecule compositions plant materials in the feeding of farm animals, replacing the similar use of prohibited feed antibiotics [50], and also determines the prospects for their testing against human pathogens that use QS to induce virulence factors and biofilm development.

Author Contributions: Conceptualization, D.D.; methodology, D.D. and K.I.; software, K.I.; formal analysis, K.I.; writing—original draft preparation, E.R.; writing—review and editing, D.D.; project administration, E.R. and G.D. All authors have read and agreed to the published version of the manuscript.

Funding: The research of the activity of coumarin and its derivatives was conducted with financial support from the research plan for 2019-2021 of the Federal state budgetary Research Center BST RAS within the framework of the thematic plan for state task No. 0526-2019-0002. The research of supra-additive effects of coumarins and plant-derived molecules was conducted with financial support from the Russian Science Foundation (Grant \#21-16-00112).

Informed Consent Statement: Not applicable.

Data Availability Statement: The data that support the findings of this study are available from the corresponding author, upon reasonable request.

Conflicts of Interest: The authors declare no conflict of interest.

Sample Availability: The materials used in the study are commercially available and can be purchased from the relevant firms.

\section{References}

1. Venugopala, K.N.; Rashmi, V.; Odhav, B. Review on Natural Coumarin Lead Compounds for Their Pharmacological Activity. BioMed Res. Int. 2013, 3, 1-14. [CrossRef] [PubMed]

2. Chua, S.L.; Liu, Y.; Li, Y.; Ting, H.J.; Kohli, G.S.; Cai, Z.; Suwanchaikasem, P.; Goh, K.K.K.; Ng, S.P.; Tolker-Nielsen, T. Reduced Intracellular c-di-GMP Content Increases Expression of Quorum Sensing-Regulated Genes in Pseudomonas aeruginosa. Front. Cell. Infect. Microbiol. 2017, 7, 451. [CrossRef] [PubMed]

3. Matos, M.J.; Santana, L.; Uriarte, E.; Abreu, O.A.; Molina, E.; Yordi, E.G. Coumarins-An Important Class of Phytochemicals. In Phytochemicals-Isolation, Characterisation and Role in Human Health; Rao, A.V., Rao, L.G., Eds.; InTech: Rijeka, Croatia, 2015; ISBN 978-953-51-2170-1.

4. Reen, F.J.; Gutierrez-Barranquero, J.A.; Parages, M.L.; O Gara, F. Coumarin: A novel player in microbial Quorum sensing and biofilm formation inhibition. Appl. Microbiol. Biotechnol. 2018, 102, 2063-2073. [CrossRef] [PubMed]

5. Cruz, L.F.; Figueiredo, G.F.; Pedro, L.P.; Amorin, Y.M.; Andrade, J.T.; Passos, T.F.; Rodrigues, F.F.; Souza, I.L.A.; Gonçalves, T.P.R.; Dos Santos Lima, L.A.R.; et al. Umbelliferone (7-hydroxycoumarin): A non-toxic antidiarrheal and antiulcerogenic coumarin. Biomed. Pharmacother. 2020, 129, 1-8. [CrossRef] [PubMed] 
6. Olanlokun, J.O.; Bodede, O.; Prinsloo, G.; Olorunsogo, O.O. Comparative antimalarial, toxicity and mito-protective effects of Diospyros mespiliformis Hochst. ex A. DC. and Mondia whitei (Hook.f.) Skeels on Plasmodium berghei infection in mice. J. Ethnopharmacol. 2020, in press. [CrossRef] [PubMed]

7. Williams, K.J.; Gieling, R.G. Preclinical Evaluation of Ureidosulfamate Carbonic Anhydrase IX/XII Inhibitors in the Treatment of Cancers. Int. J. Mol. Sci. 2019, 23, 6080. [CrossRef]

8. Akkol, E.K.; Genç, Y.; Karpuz, B.; Sobarzo-Sánchez, E.; Capasso, R. Coumarins and Coumarin-Related Compounds in Pharmacotherapy of Cancer. Cancers 2020, 7, 1959.

9. Shahzadi, I.; Ali, Z.; Baek, S.H.; Mirza, B.; Ahn, K.S. Assessment of the Antitumor Potential of Umbelliprenin, a Naturally Occurring Sesquiterpene Coumarin. Biomedicines 2020, 5, 126. [CrossRef]

10. Nasser, M.I.; Zhu, S.; Hu, H.; Huang, H.; Guo, M.; Zhu, P. Effects of imperatorin in the cardiovascular system and cancer. Biomed. Pharmacother. 2019, 120, 109401. [CrossRef]

11. Duan, J.; Shi, J.; Ma, X.; Xuan, Y.; Li, P.; Wang, H.; Fan, Y.; Gong, H.; Wang, L.; Pang, Y.; et al. Esculetin inhibits proliferation, migration, and invasion of clear cell renal cell carcinoma cells. Biomed. Pharmacother. 2020, 125, 110031. [CrossRef]

12. Usman, H.; Ullah, M.A.; Jan, H.; Siddiquah, A.; Drouet, S.; Anjum, S.; Giglioli-Guviarc'h, N.; Hano, C.; Abbasi, B.H. Interactive Effects of Wide-Spectrum Monochromatic Lights on Phytochemical Production, Antioxidant and Biological Activities of Solanum Xanthocarpum Callus Cultures. Molecules 2020, 9, 2201. [CrossRef] [PubMed]

13. Urbagarova, B.M.; Shults, E.E.; Taraskin, V.V.; Radnaeva, L.D.; Petrova, T.N.; Rybalova, T.V.; Frolova, T.S.; Pokrovskii, A.G.; Ganbaatar, J. Chromones and coumarins from Saposhnikovia divaricata (Turcz.) Schischk. Growing in Buryatia and Mongolia and their cytotoxicity. J. Ethnopharmacol. 2020, 261, 112517. [CrossRef] [PubMed]

14. Bihani, T. Plumeria rubra L.-A review on its ethnopharmacological, morphological, phytochemical, pharmacological and toxicological studies. J. Ethnopharmacol. 2021, 264, 113291. [CrossRef] [PubMed]

15. Starzak, K.; Świergosz, T.; Matwijczuk, A.; Creaven, B.; Podleśny, J.; Karcz, D. Anti-Hypochlorite, Antioxidant, and Catalytic Activity of Three Polyphenol-Rich Super-Foods Investigated with the Use of Coumarin-Based Sensors. Biomolecules 2020, 10, 723. [CrossRef] [PubMed]

16. Zeng, Z.; Qian, L.; Cao, L.; Tan, H.; Huang, Y.; Xue, X.; Shen, Y.; Zhou, S. Virtual screening for novel quorum sensing inhibitors to eradicate biofilm formation of Pseudomonas aeruginosa. Appl. Microbiol. Biotechnol. 2008, 79, 119-126. [CrossRef]

17. Takomthong, P.; Waiwut, P.; Yenjai, C.; Sripanidkulchai, B.; Reubroycharoen, P.; Lai, R.; Kamau, P.; Boonyarat, C. Structure-Activity Analysis and Molecular Docking Studies of Coumarins from Toddalia asiatica as Multifunctional Agents for Alzheimer's Disease. Biomedicines 2020, 8, 107. [CrossRef]

18. Janus, Ł.; Radwan-Pragłowska, J.; Piątkowski, M.; Bogdał, D. Coumarin-Modified CQDs for Biomedical Applications-Two-Step Synthesis and Characterization. Int. J. Mol. Sci. 2020, 21, 8073. [CrossRef]

19. Lee, E.J.; Kang, M.K.; Kim, Y.H.; Kim, D.Y.; Oh, H.; Kim, S.I.; Oh, S.Y.; Na, W.; Kang, Y.H. Coumarin Ameliorates Impaired Bone Turnover by Inhibiting the Formation of Advanced Glycation End Products in Diabetic Osteoblasts and Osteoclasts. Biomolecules 2020, 10, 1052. [CrossRef]

20. Koga, H.; Negishi, M.; Kinoshita, M.; Fujii, S.; Mori, S.; Ishigami-Yuasa, M.; Kawachi, E.; Kagechika, H.; Tanatani, A. Development of Androgen-Antagonistic Coumarinamides with a Unique Aromatic Folded Pharmacophore. Int. J. Mol. Sci. 2020, $21,5584$. [CrossRef]

21. Zhang, S.; Liu, N.; Liang, W.; Han, Q.; Zhang, W.; Li, C. Quorum sensing-disrupting coumarin suppressing virulence phenotypes in Vibrio Splendidus. Appl. Microbiol. Biotechnol. 2016, 101, 3371-3378. [CrossRef]

22. Gutiérrez-Barranquero, J.A.; Reen, F.J.; McCarthy, R.R.; O'Gara, F. Deciphering the role of coumarin as a novel quorum sensing inhibitor suppressing virulence phenotypes in bacterial pathogens. Appl. Microbiol. Biotechnol. 2015, 99, 3303-3316. [CrossRef] [PubMed]

23. Hou, H.M.; Jiang, F.; Zhang, G.L.; Wang, J.Y.; Zhu, Y.H.; Liu, X.Y. Inhibition of Hafnia alvei H4 Biofilm Formation by the Food Additive Dihydrocoumarin. J. Food Prot. 2017, 12, 842-847. [CrossRef] [PubMed]

24. D'Almeida, R.E.; Molina, R.D.I.; Viola, C.M.; Luciardi, M.C.; Nieto Peñalver, C.; Bardón, A.; Arena, M.E. Comparison of seven structurally related coumarins on the inhibition of Quorum sensing of Pseudomonas aeruginosa and Chromobacterium violaceum. Bioorg. Chem. 2017, 73, 37-42. [CrossRef] [PubMed]

25. Girennavar, B.; Cepeda, M.L.; Soni, K.A.; Vikram, A.; Jesudhasan, P.; Jayaprakasha, G.K.; Pillai, S.D.; Patil, B.S. Grapefruit juice and its furocoumarins inhibits autoinducer signaling and biofilm formation in bacteria. Int. J. Food Microbiol. 2008, 125, 204-208. [CrossRef] [PubMed]

26. Inchagova, K.S.; Duskaev, G.K.; Deryabin, D.G. The suppression of the "quorum sensing" Chromobacterium violaceum when exposed to combinations of amikacin with activated carbon or small molecules of plant origin (pyrogallol and coumarin). Microbiology 2019, 88, 72-82. [CrossRef]

27. Deryabin, D.G.; Inchagova, K.S. Inhibitory effect of aminoglycosides and tetracyclines on Quorum sensing in Chromobacterium violaceum. Microbiology 2018, 87, 1-8. [CrossRef]

28. Abate, A.; Dimartino, V.; Spina, P.; Costa, P.L.; Lombardo, C.; Santini, A.; Del Piano, M.; Alimonti, P. Hymecromone in the treatment of motor disorders of the bileducts: A multicenter, double-blind, placebo-controlled clinical study. Drugs Exp. Clin. Res. 2001, 27, 223-231.

29. Božič-Mijovski, M. Advances in monitoring anticoagulant therapy. Adv. Clin. Chem. 2019, 90, 197-213. [CrossRef] 
30. Dávila-Fajardo, C.L.; Díaz-Villamarín, X.; Antúnez-Rodríguez, A.; Fernández-Gómez, A.E.; García-Navas, P.; Martínez-González, L.J.; Dávila-Fajardo, J.A.; Barrera, J.C. Pharmacogenetics in the treatment of cardiovascular diseases and its current progres regarding implementation in the clinical routine. Genes 2019, 10, 261. [CrossRef]

31. Opherk, D.; Schuler, G.; Waas, W.; Dietz, R.; Kubler, W. Intravenous carbochromen: A potent and effective drug for estimation of coronary dilatory capacity. Eur. Heart J. 1990, 11, 342-347. [CrossRef]

32. Gierlak, W.; Kuch, M. How to use cardiac drugs in everyday practice? In Anticoagulants in Cardiology-Vitamin K Antagonists; Czelej, Lublin 1.; 2010; Chapter 6.

33. Salvo, F.; Bezin, J.; Bosco-Levy, P.; Letinier, L.; Blin, P.; Pariente, A.; Moore, N. Pharmacological treatments of cardiovascular diseases: Evidence from real-life studies. Pharmacol. Res. 2017, 118, 43-52. [CrossRef] [PubMed]

34. Patel, D.; Patel, R.; Kumari, P.; Patel, N. In vitro antimicrobial assessment of coumarin-based s-triazinyl piperazines. Med. Chem. Res. 2012, 21, 1611-1624. [CrossRef]

35. López, F.; Deglesne, J.; Arroyo, P.A.; Ranneva, R.; Deprez, E. 4hexylresorcinol-a-new-molecule-for-cosmetic-application. J. Biomol. Res. Ther. 2018, 8, 1000170.

36. Aguedo, M.; Beney, L.; Waché, Y.; Belin, J.M. Interaction of an odorant lactone with model phospholipid bilayers and its strong fluidizing action in yeast membrane. Int. J. Food Microbiol. 2003, 80, 211-215. [CrossRef]

37. Inchagova, K.S.; Deryabin, D.G.; Duskaev, G.K.; Karimov, I.F.; Ryazanov, V.A. Plant molecules influence on luminescent Escherichia coli K12 TG1 with1constitutiveexpressed luxCDABE genes. FEBS OpenBio 2019, 9, 303-304.

38. Zhang, J.; Jiang, C.S. Synthesis and evaluation of coumarin/piperazine hybrids as acetylcholinesterase inhibitors. Med. Chem. Res. 2018, 27, 1717-1727. [CrossRef]

39. Brackman, G.; Hillaert, U.; Van Calenbergh, S.; Nelis, H.J.; Coenye, T. Use of quorum sensing inhibitors to interfere with biofilm formation and development in Burkholderia multivorans and Burkholderia cenocepacia. Res. Microbiol. 2009, 160, 144-151. [CrossRef]

40. Lindsay, A.; Ahmer, B.M. Effect of sdiA on biosensors of N-acylhomoserine lactones. J. Bacteriol. 2005, 187, 5054-5058. [CrossRef]

41. Ding, X.; Yin, B.; Qian, L.; Zeng, Z.; Yang, Z.; Li, H.; Lu, Y.; Zhou, S. Screening for novel quorum-sensing inhibitors to interfere with the formation of Pseudomonas aeruginosa biofilm. J. Med. Microbiol. 2011, 60, 1827-1834. [CrossRef]

42. Durig, A.; Kouskoumvekaki, I.; Vejborg, R.M.; Klemm, P. Chemoinformatics-assisted development of new anti-biofilm compounds. Appl. Microbiol. Biotechnol. 2010, 87, 309-317. [CrossRef]

43. Todorov, L.; Traykova, M.; Traykov, T. In Vitro Evaluation of the Antioxidant Effect of Yohimbine, Proceedings of the IV European Congress on Toxicology; EUROTOX: Krakow, Poland, 2005; Poster No. 27.

44. Tyagi, Y.K.; Kumar, A.; Raj, H.G.; Vohra, P.; Gupta, G.; Kumari, R.; Kumar, P.; Gupta, R.K. Synthesis of novel amino and acetyl amino-4-methylcoumarins and evaluation of their antioxidant activity. Eur. J. Med. Chem. 2005, 40, 413-420. [CrossRef] [PubMed]

45. Yang, L.; Ding, W.; Xu, Y.Q.; Wu, D.S.; Li, S.L.; Chen, J.N.; Guo, B. New insights into the antibacterial activity of hydroxycoumarins against Ralstonia Solanacearum. Molecules 2016, 21, 468. [CrossRef] [PubMed]

46. Lee, J.H.; Kim, Y.G.; Cho, H.S.; Ryu, S.Y.; Cho, M.H.; Lee, J. Coumarins reduce biofilm formation and the virulence of Escherichia coli O157:H7. Phytomedicine 2014, 21, 1037-1042. [CrossRef] [PubMed]

47. Deryabin, D.G.; Kamayeva, A.A.; Tolmacheva, A.A.; El-Registan, G.I. The effects of alkylhydroxybenzenes on homoserine lactone-induced manifestations of quorum sensing in bacteria. Appl. Biochem. Microbiol. 2014, 50, 353-358. [CrossRef]

48. Stauff, D.L.; Bassler, B.L. Quorum sensing in Chromobacterium violaceum: DNA recognition and gene regulation by the CviR receptor. J. Bacteriol. 2011, 193, 3871-3878. [CrossRef]

49. Tallarida, R.J. An overview of drug combination analysis with isobolograms: Perspectives in pharmacology. Pharmacol. Exp. Ther. 2006, 3, 1-7. [CrossRef]

50. Landers, T.F.; Cohen, B.; Wittum, T.E.; Larson, E.L. A review of antibiotic use in food animals: Perspective, policy, and potential. Public Health Rep. 2012, 127, 4-22. [CrossRef] 